\title{
10
}

\section{A Study of On-the-Go Reference Service Using Mobile Technology in Library}

Subhajit Panda

\section{Abstract}

Libraries all over the world are continually reinventing themselves to meet changing community needs and the increasing opportunities and associated challenges that modern and evolving technologies bring. In response to the current pandemic and to follow the government guidelines about the remote learning program libraries \& librarians face a huge need for real-time information from the faculty, staff member, students, and researcher. On another side, financial crisis $\&$ cutting budget, unavailability of adequate staff, user awareness, etc. are the main issues faces by libraries while try to adopt new technologies for accepting the challenges \& issues created by this pandemic. On this point, mobile technology, as an economical \& affordable technological solution that helps libraries to keep abreast of the dynamically changing needs of their clientele and identify the way of delivering user-centered services by surveying the user needs. The current study examines the exponential growth in the mobile communication system, both in terms of technology (generation) \& user count, after considering the needs of the user community. Besides, the study sets out the basic steps for introducing a mobile reference service in a library, as well as its future uses and benefits. 
Keywords: Digital reference services, Mobile generations, $0 G, 1 G, 2 G$, $3 G, 4 G, 5 G$, Mobile reference services, Mobile technology, Reference service, Future trends

\section{Introduction}

There is no doubt that Mobile phones have become an inseparable part of everyday life. Jacobs observes that "everywhere we go we cannot help but notice the number of mobile devices being used; cell phones, iPod, MP3 players, GPS systems, blackberries, and even mini-laptops. Mobile access is the remediation of wireless internet" (Jacobs, 2009). The current digital communication system emerged from the need for it. This system developed at an unprecedented pace, owing primarily to the proliferation \& growth of mobile gadgets and the mobile user base, which prompted the development of several new generations of mobile communication systems, each of which outperformed the previous in terms of speed \& operation. This development has had an impact on the library's ability to deliver services to mobile users. The networked digital environment facilitates easy access to library resources without any geographical or time restrictions, made library resources more visible \& useful to the users. According to Murray, by providing these specialized services to their users, the libraries not only "provide new services or enhance traditional services, but also make it more relevant to their users" (Murray, 2010).

\section{Literature Review}

For a better understanding of the current study, some insightful research that visualizes the basic principle of the use of mobile technology in reference services is discussed here.

Shahzad et al. (2020) improved the general process model (GPM) by incorporating the new components with increased service efficiency by reducing the response time from days to seconds for repeated questions and decreased the workload of librarians. Singh (2012) attempted to make a comparison of University libraries in Northern India based on digital Reference Services and Online/ Digital Service being provided by these libraries. In their study, Barnhart \& Pierce (2011) displayed how a library can become ubiquitous by making resources \& services available anytime $\&$ anywhere. Furthermore, they also studied how reference librarians can use mobile devices \& applications to include services in the mobile library environment. Kataria \& Anbu K (2011) discussed the overall impact of mobile services \& applications in libraries and additionally identified 
the area of Reference assistance in the libraries where the potential, demand \& opportunities are more for mobile applications. Hudson (2010) provided evidence that cultural diversity and gender impact desired mobile device reference services among undergraduate students. In general, libraries, that already offer some type of reference service geared toward people who use mobile devices, generally focus on the reference transaction, Lippincott, (2009) discussed some of the broader aspects of service, including the availability of content for mobile devices and the relationship of the library's services to mobile initiatives on campus. Tao et al. (2009), in their survey-based research, focused on how the Mobile Reference Service program has enhanced library funding for study \& scholarship, cultivated \& reinforced liaison partnerships, and improved promotion \& distribution of library resources \& services to the Saint Louis University School of Public Health.

\section{Objectives of the Study}

The main aim of the present study is to discuss the introduction of mobile technology as economic development in library reference services. The primary objectives of this study are:

- To discuss in brief, the needs of the use of mobile technology in reference service.

- To examine growth in the mobile communication system in terms of the development of new generation and growth of user base.

- To structure the basic steps to introduce mobile reference services in a library.

- To show the possible applications of mobile technology to support reference services in the library.

- To examine the benefits of mobile technology in providing reference services

\section{Needs of the Study}

The advent of ICT applications into library services, especially instant messaging services enhanced web-based reference service, or digital reference service, or virtual reference service. The invention of mobile phones is such a vital achievement of technological developments (S. \&P., 2013) and playing a very significant role in user's information-seeking behavior in such a way teaching, learning, and research work as per users' need (Singh \& Nikandia, 2017). Libraries being the sanctum sanctorum of any institution of higher education, have always grabbed the opportunity 
to provide unparalleled initiative and support to the growth of academic institutions (Paul, 2016).

Apart from the new age technological intervention \& updation Mobile Library services also plays important role in the current situation viz. New Normal. In response to the pandemic government ordered to strictly comply with the guidelines of UGC about the remote learning program from school to higher education institutions. In this situation, libraries \& librarians face a huge need for real-time information - not only from the faculty \& staff members but also from the students to complete their semester coursework. For this reason, librarians now try to adapt their own institution's initiatives and also how other libraries were responding (Hinchliffe \& Eisenberg, 2020). The loss of conventional communication medium \& channel, lockdown \& social distancing, absence of physical presence of library user, disruption of formal library services, etc. create a need for changes in the way libraries provide services to their users. And on the other side, financial crisis \& cutting budget, unavailability of adequate staff, user awareness, etc. are the main issues faces by libraries while try to adopt new technologies for accepting the challenges \& issues created by this pandemic. These are challenging economic times for libraries to take on new technological initiatives, yet librarians across the country and internationally are seeking creative solutions to providing mobile library services (Rahane, 2018). On this point, mobile technology, as an economical \& affordable technological solution that helps libraries to keep abreast of the dynamically changing needs of their clientele and identify the way of delivering user-centered services by surveying the user needs (Panda, 2020).

\section{Growth in Mobile Communication System}

Mobile communication between mobile users or between mobile \& fixed line users (Lin et al., 2017). There is no doubt that mobile and satellite communications are triggering a wave of unprecedented growth and people are becoming more dependent on wireless communication systems (Olatokun \& Bodunwa, 2006).

\section{Development of Generation}

"Generation" typically refers to a shift in the fundamental nature of the service in the field of mobile communications. It is associated with nonbackward-compatible transmission technology, higher peak bit rates, new frequency bands, wider channel frequency bandwidth in Hertz, and higher capacity for many simultaneous data transfers. (Bartlett, 2019) 


\section{Table 1}

\begin{tabular}{|c|c|c|c|c|c|c|}
\hline $\begin{array}{l}\text { S. } \\
\text { N. }\end{array}$ & Gen & $\begin{array}{c}\text { Launch } \\
\text { Year }\end{array}$ & Technology & $\begin{array}{l}\text { Signal } \\
\text { Type }\end{array}$ & $\begin{array}{l}\text { Network } \\
\text { Speed }\end{array}$ & Remarks \\
\hline 1 & $0 \mathrm{G}$ & 1946 & $\begin{array}{l}\text { PTT, MTS, } \\
\text { IMTS, AMTS }\end{array}$ & Analogue & - & $\begin{array}{l}\text { Mobile } \\
\text { radiotelephone } \\
\text { systems, pre-cellular } \\
\text { era }\end{array}$ \\
\hline 2 & $1 \mathrm{G}$ & 1979 & $\begin{array}{l}\text { AMPS, } \\
\text { NMT, TACS, } \\
\text { C-Netz }\end{array}$ & Analogue & $\begin{array}{l}2.4-15 \\
\text { Kbps }\end{array}$ & $\begin{array}{l}\text { launched by Nippon } \\
\text { Telegraph and } \\
\text { Telephone (NTT) in } \\
\text { Tokyo }\end{array}$ \\
\hline 3 & $2 \mathrm{G}$ & 1991 & $\begin{array}{l}\text { GSM, } \\
\text { D-AMPS, } \\
\text { IS-95 A }\end{array}$ & Digital & $\begin{array}{l}110-500 \\
\text { Kbps }\end{array}$ & $\begin{array}{l}\text { launched under the } \\
\text { GSM standard in } \\
\text { Finland }\end{array}$ \\
\hline 4 & $3 G$ & 2001 & $\begin{array}{l}\text { UMTS, } \\
\text { CDMA2000 }\end{array}$ & Digital & $\begin{array}{l}2-50 \\
\text { Mbps }\end{array}$ & $\begin{array}{l}\text { launched by NTT } \\
\text { DoCoMo }\end{array}$ \\
\hline 5 & $4 \mathrm{G}$ & 2009 & LTE & Digital & $\begin{array}{l}300 \\
\text { Mbps- } 3 \\
\text { Gbps }\end{array}$ & $\begin{array}{l}\text { deployed in } \\
\text { Stockholm, Sweden } \\
\text { and Oslo, Norway } \\
\text { as the Long Term } \\
\text { Evolution (LTE) 4G } \\
\text { standard }\end{array}$ \\
\hline 6 & $5 \mathrm{G}$ & $\begin{array}{c}2016 \\
\text { onward }\end{array}$ & NR & Digital & $\begin{array}{l}10 \text { Gbps } \\
\& \text { More }\end{array}$ & developed by 3GPP \\
\hline
\end{tabular}

[Source: Ghayas (2020), Lin et al. (2017)]

Looking back, the development of mobile communication has gone through several stages of development.

After World War-II, the wireless telephone started with first-generation cellular telephone predecessors, are called 0G (Zero Generation) Systems. Among those wireless technologies, PTT (Push to Talk), MTS (Mobile Telephone System), IMTS (Improved Mobile Telephone Service), AMTS (Advanced Mobile Telephone System), OLT (Norwegian for Offentlig Landmobil Telefoni, Public Land Mobile Telephony) \& MTD (Swedish abbreviation for Mobile Telephony System D) are significant ones. In between $0 \mathrm{G} \& 1 \mathrm{G}, 0.5 \mathrm{G}$ is a group of technologies with an improved feature than the basic 0G and sold through WCCs (Wireline Common Carriers, AKA telephone companies), RCCs (Radio Common Carriers), and two-way radio dealers, e.g. Autoradiopuhelin \& B-Netz.

The first generation of mobile communication technology mainly refers to cellular analog mobile communication \& frequency division multiple 
access (FDMA) technology. It is associated with Traffic \& Control logical channels e.g. the United States's AMPS system, the British ETACS system, the French 450 system, the Nordic NMT 450 system and China's TAOS system, the Japanese NTT, and so on (Lin et al., 2017).

The second-generation launched with a rapid development of mobile communication technology starting from analog to digital mobile communication technology and set up of Group special mobile (GSM) under the European Telecommunications Standards Institute (ETSI) Technical Committee. With continual development \& amendment from time to time, the second generation ranges from $2.0 \mathrm{G}$ to $2.75 \mathrm{G}$. TDMA e.g. GSM, PDC, iDEN \& iS-136, and CDMA e.g. iS-95 are the primarily associated technologies with the second generation. In extension to $2.0 \mathrm{G}, 2.5 \mathrm{G}$ can launch GPRS (General Packet Radio Service), and 2.75G introduced EDGE (Enhanced Data rates for GSM Evolution).

The third generation of mobile phone technology is based on the plan of the International Telecommunication Union (ITU), called International Mobile Telephone 2000 (IMT-2000), Standard. In extension to 3.0G, the third generation mobile communication also includes 3.5G: HSDPA (HighSpeed Downlink Packet Access) and 3.75G: HSUPA (High-Speed Uplink Packet Access) based on UMTS / WCDMA uplink evolution technology.

Under the combined action of new technology and market demand, the fourth generation of the mobile communication system with the must-have capabilities defined by ITU in IMT Advanced. Also, potential \& current applications include amended mobile web access, IP telephony, gaming services, high-definition mobile TV, video conferencing, \& 3D television.

The industry association 3GPP developed the fifth generation of cellular network technology using "5G NR" (5G New Radio) software. In addition to existing $2 \mathrm{G}, 3 \mathrm{G}, 4 \mathrm{G}$, and their respective associated technologies (such as GSM, UMTS, LTE, LTE Advanced Pro, and others); 5G NR also addresses specific requirements for private mobile networks ranging from industrial IoT to critical communications. South Korea has become the first nation in Asia to launch commercial 5G networks after three carriers, KT, LG U Plus, and SK Telecom (Morris, 2018).

\section{Growth of User Base}

With the increasing popularity of mobile devices, the demand for mobile communication technology continues to rapidly grow all around the world. The global mobile data traffic, for example, is forecast to increase from 7 exabytes per month in 2016 to 49 hex bytes per month by 2021 . By 2022 the total number of mobile subscriptions worldwide is forecast to grow to more than nine billion. (Holst, 2018) 


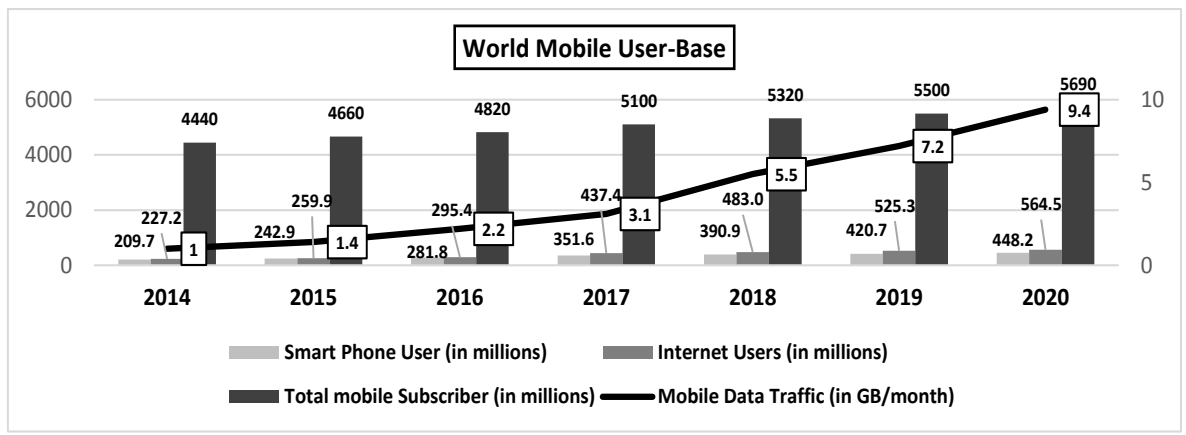

Figure 1

[Source: Asher (2020), Internet World Stats (2020) \& O’Dea (2020, 2021)]

Figure 1 above displays the annual growth (in millions) of the world mobile user-base from 2014 to 2020 considering 'smartphone user', 'internet users' \& 'total mobile subscriber' as parameters. Further, the figure also shows the consecutive growth (in GB/month) of 'mobile data traffic' for that particular period.

\section{Mobile Reference Services}

Among the many services that are capable of changing the library landscape, mobile reference is one of the foremost that has affected library services. Given the advent of mobile phones for every aspect of library services, there is no doubt that many libraries have started planning for Mobile Reference Services (Anbu \& Kataria, 2016). Jason Griffey (2010) predicted that the future of mobile technology involves three main areas: location-based services, personally networked devices, and ubiquitous connectivity. He predicted that the reference services will increasingly move to the mobile interface where most transactions will be completely virtual.

\section{Steps to Implement Mobile Library Services}

\section{Identify the Framework}

Usually, identifying the framework for integrating mobile reference services in a library environment can be understood by exercising Figure 2 above. A mobile user study is outmost necessary before developing a strategy \& structuring system for mobile reference services. After ensuring adequate availability of mobile users, the implementation area was determined with a needs analysis. 
90 Re-Envisioning Roles and Responsibilities of Library Professionals in...

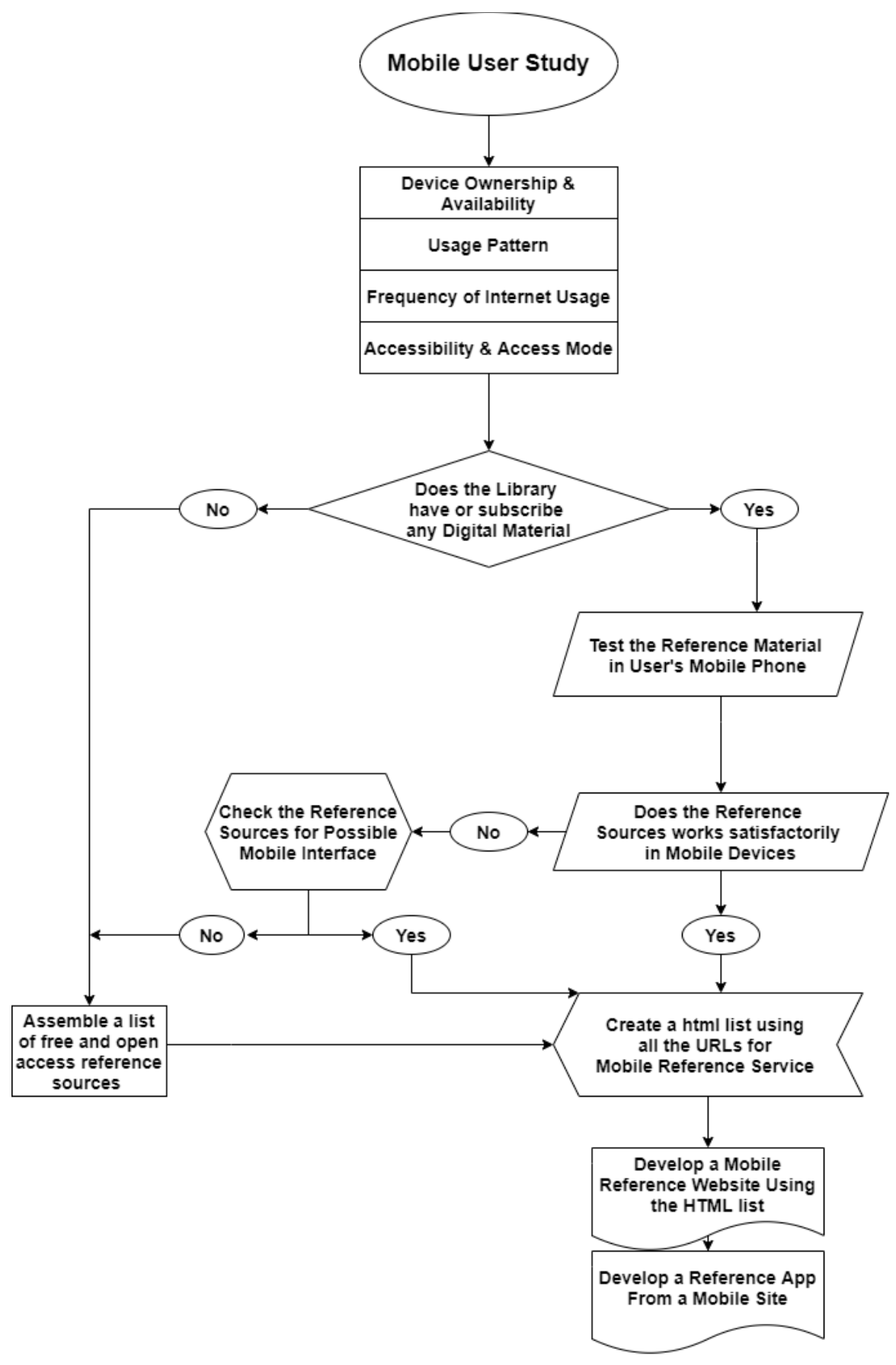

Figure 2 


\section{Need Analysis}

In the present Coronavirus crisis, it now becomes a huge problem for the library and information professionals in disseminating information to their users. Now librarians have become needy for implementing such a technological device that is economical, affordable, and can face the challenge of information sharing to the remote user (Panda, 2020). Mobile-based reference library services helped librarians to well reach out to the remote users who were considered unlikely to connect because of the absence of a medium. Additionally, specialized and personalized information services can be achieved using the wireless technologies made available to all, anytime \& anywhere.

\section{Mobile Infrastructure \& Availability of Staffing}

Mobile devices today can run increasingly complex software, interact with cloud services, play rich multimedia content, and allow for advanced user interactivity. New hardware and technologies such as Bluetooth, accelerometers, and multi-touch screens, as well as text, messaging, android phone software applications, mobile websites, global positioning systems (GPS), Wi-Fi, Bluetooth, mobile hotspot, share it, and media creation and capture tools, are all part of the mobile environment (Rahane, 2018).

Mobile technology is the easiest \& simplified technology among other ICT components. It is easy to understand, carry \& economically affordable. No specialized skills of currently employed Information Technology staff required while starting the implementation of mobile reference service.

\section{Resource Identification}

Reference services fulfill the last part of library information services, viz. acquire information, organize acquired information, and disseminate organized information. A library needs to be assured about the sufficient availability of digital contents in library collection before launching the mobile reference service. Also, it is essential to verify whether or not all digital materials available are compatible with mobile devices. If not, the library needs to subscribe to digital resources to put in the Mobile Reference Desk. After the acquisition of adequate resources, the hyperlinks of URLs are arranged according to the target user groups and distributed as per requirement arises.

\section{Implementation}

After thoroughly going through the above-mentioned steps, the final implementation is accomplished when the organizing committee of a library 
is satisfied with its current situation (i.e. availability of infrastructure \& resources, \& quality of staff) to meet the requirements for implementing mobile reference services in the library. Moreover, to continue such services user's feedback is also taken into consideration.

\section{Types of Mobile Reference Services}

Short Range Reference Services: With the aid of reference books, short-range or ready reference services address fact-finding questions that can be answered in a very short time or, if possible, a moment. In mobile reference services, short-range reference services are the most commonly asked ones. Important reference sources are now increasingly available as mobile reference sources for users. Mobile dictionaries, encyclopedias \& thesaurus are most common among them. These resources can be available both in web \& mobile app form. Some of them are free, some are subscriptionbased, and the rest offers both of the choices. Some examples of such sources as follows: Advanced English Dictionary and Thesaurus (Free/ \$0.99); Dict. cc (Free/ \$0.99); Dict Box Offline Dictionary (Free/ \$4.49), Dictionary by The Free Dictionary (Free/ \$1.99), Dictionary.com (Free/ \$2.99), MerriamWebster Dictionary (Free/ \$2.99), the concise Encyclopaedia Britannica (Subscription based), the Big English Encyclopaedia 8.3 (Subscription based), Encyclopedia.com (Free) etc.

Long Range Reference Services: Long-range reference services cannot be offered immediately. Just a few long-range reference questions take less than half an hour, while others take an entire day or even weeks to complete. The quest for information in a long-range reference service begins with ready information reference services and continues into ordinary books, papers, periodicals, etc. If information is not available in the library, the quest can be extended to include other libraries' resources, as well as libraries in other areas of the world. For long-range online reference services, the most prevalent platform is e-mail.

Email Services: In broad research and academic institutions, e-mail reference services have become a popular service. The user sends an e-mail with a reference question to the library, offering whatever data he or she thinks is appropriate. The library can answer by e-mail, telephone, fax, text, etc. The e-mail facility is used widely by many libraries and information centers to provide mobile reference services for a long-term query.

Mobile Library Website: In the case of internet-mediated information dissemination, websites become relevant among the most popular and useful means of disseminating information to the common people in any area of our society. The mobile library website is the primary component of introducing mobile reference services. The use of CSS (Cascading Style 
Sheets) or ADR (Auto-Detect and Reformat Software) will turn a library website into a mobile-friendly interface, allowing it to rearrange its control $\&$ navigation to fit the size of the screen it is being displayed on (Maideen, 2017). Many of the above-mentioned reference service channels can be linked with the mobile library website.

Mobile Library App: Mobile applications are dedicated pieces of software or web applications/sites that enhance mobile device's capabilities and access information in an elegant, consistent way, and are the means for creating new services for mobile patrons. Mobile library applications can be a valuable way to disseminate information to library users in the new environment of social distancing and lockdown. It is also possible to incorporate mobile library applications with the main library website, library Web-OPAC \& library digital resources.

Mobile FAQ Database: The library should build up a mobile-friendly FAQ database associated with mobile library websites or mobile library apps, integrated with general queries about the library, e-news clipping, digital resources of the library, and also connect with many other free online reference sources.

Mobile SMS: Mobile SMS or simple chat reference services are popular means of instant communication in the form of text messages over the mobile network. Mobile phone number is the primary address to send this kind of SMS \& if the receiving party active at that time s/he can reply immediately. Reference librarians can use Mobile SMS services as a quick $\&$ cost-effective forum to respond to the essential queries of the library users.

Instant Messing: Instant Messaging is an increasingly common alternative method of chat communication. Instant Messaging has various useful features to support mobile reference services. Users have to install client applications on their mobile to make use of these. In this program, users can produce their address lists, so-called buddy lists and can check who else is online when they logged in. Many university libraries including, American University, Monash University \& Rice University have implemented this type of mobile reference system which is very costeffective and reliable. In IM gateways, as soon as the user sends a reference query as an SMS it reaches the library in form of an email. Once the library sends the reply through Email, it arrives at the user's end as an SMS.

Chatbot: To provide $24 * 7$ user support without human intervention librarians can refer to the use of messaging apps, voice-based assistants, and chatbots to automate communication for personalized user experiences. Chatbots are technically similar to full-text search engines, but they portray the illusion of an online chat: the users enter their queries in the 
fields provided and receive immediate replies (Singh, 2012). The real power of a chatbot, to the extent of other common messaging services, lies in its ability to simultaneously carry out highly personalized interactions with large numbers of individual library users.

\section{VolP (Audio-Chat or Internet Phoning)}

Voice over Internet Protocol (VoIP) is a technology that enables the transfer of voice and other data via the standard internet protocol (TCP/ IP). In simple chat references, sometimes it is impossible to understand the actual query from a user, and the reference librarian unable to answer it satisfactorily. At this point, VoIP or Internet phoning is crucial, particularly in targeting digital users.

Real-time live web-reference: Real-Time web reference is a new trend that helps the library to deliver reference information to its users on mobile and web applications in near real-time. Delivering real-time updates (e.g. CAS, SDI \& News Clipping services) is a critical workload for many libraries with large multidisciplinary user-base. This solution simplifies historically complex and expensive infrastructure and helps support thousands of users tracking the latest updates on a web or mobile application. Flexibility for data/feed ingestion, live updates \& push notifications are the beneficial features of popular web-referencing tools.

Online Pathfinders: Online pathfinders are subject-gateway designed to find information on a particular topic compatible with web-as-well-as mobile devices. With more and more information available in electronic format and on the web, online pathfinders are becoming increasingly popular, e.g. Library of Congress (www.loc.gov) website and Internet Public Libran (ipl.org). For example, Library, Net library, Internet Public Library Pathfinders, and Pathfindersonline.org.

Mobile Reference Services for Disabled Persons: The use of mobile technology for providing reference services is beneficial to assist persons with special abilities like visual or hearing impairments. Such people are often unable to access it because there is no special interface for them. Mobile devices such as smartphones have screen readers that can help the disabled to access information. Visual or vibrating alerts devices, voice recognition, and auto-text make mobile phones accessible for persons with physical disabilities. For example LibriVox (Free access to over 24,000 audiobooks). If any library provides such members with the gateway of Libri Vox they can use it through their mobile phone.

Mobile Referral Services (Collaborative Network): Referral service is an extension of reference service where the users are directed to 
the place outside the parental library wherefrom the information can be retrieved. In this service, two or more libraries of the same discipline or locality pair up to offer reference services using either of the above online formats. The user would send to a member library his or her request, which would be forwarded to the library best able to answer the question. A library may get a question routed to it because it has particular strengths in its collection that match the needs of the user. Or a member library might get a question routed to it because it happens to be open when the user makes his or her request.

\section{Advantages of Mobile Reference Services in Libraries}

Mobile technology offers an economical way to upgrade \& improve the efficiency of library services by allowing a fast exchange of information and easy access to library services among multiple library users at the same time even while they are moving. Among the others, reference services also apply mobile technology to deliver information \& respond to users' queries in less possible time \& without any geographical restriction. Following are some key benefits of the use of mobile technology in providing reference services:

- User Friendly: Most library users use mobile phones and they easily access web-based information provided by their library.

- Personalized service: In the mobile reference services users may be categorized in many sections and according to their needs library provides specialized information services to them.

- Saves Time: It saves users time, users need not be required to come to the library, from their mobile phones they can put their query, get a response \& reach the reference librarian easily.

- No Geographical restrictions: From any part of the global users can use library reference services i.e. any kind of information they need only with a mobile device \& active internet connection.

- Multi-Respond services: Mobile reference system with integration of conversational AI viz, chatbot or Ask a librarian, can respond multiple users at the same time with multiple queries.

- Active user participation: With the use of mobile technology, the reference desk now looks like a discussion forum \& more interactive by adding chat rooms, blogs, social interface, etc.

- Scalability: The scalability of the mobile reference service improved significantly with the inclusion of a mobile referral service and a discussion forum. Now the queries of a library user are not only available to respond with reference librarian of a single library, 
other reference librarians of the same subject discipline or locality, even with other library user \& academician of that forum are also eligible to join the discussion.

- Quick feedback: Through mobile technology, users can give quick feedback related to library reference service and get quick responses related to their queries.

\section{Conclusion}

To assist the user community in learning, work, recreation, creativity \& innovation, the reference \& information services continues their services in a unique position. The task for library leaders is to evaluate the library's influence in their local community, and there is space for further study in this field in the future. Despite the challenges of a rapidly changing world, libraries in the present era will continue to link people to knowledge, assisting them in discovering what they need and inspiring them to achieve their objectives (Thorpe, 2017). Similarly, at the present pandemic situation \& lockdown libraries \& librarians are offering online resources \& services to their users proactively \& enthusiastically. The present study creates awareness \& promotes the benefits of using mobile reference services in a library with a detailed discussion about the primary steps of introduction and its possible application. The possible extension of the contemporary study includes the actual perception of Indian librarians about the introduction of mobile reference services in their libraries, the users' acceptance rate, and the possible challenges in this introduction process.

\section{References}

[1] Anbu, J. P., \& Kataria, S. (2016). Reference on the Go: A Model for Mobile Reference Services in Libraries. The Reference Librarian, 57(3), 235-241. https://doi.org/10.1080/02763877.2015.1132181

[2] Asher, V. (2020, August 11). Number of smartphone users in India 20152022 | Statista. https://bit.ly/31uTqJ0

[3] Barnhart, F. D., \& Pierce, J. E. (2011). Becoming Mobile: Ref Becoming Mobile: Reference in the Ubiquitence in the Ubiquitous Library. Journal of Library Administration, 51(3), 279-290.

[4] Bartlett, M. (2019, November 26). The Evolution of Mobile Wireless Technology from 0G to 5G. Medium. https://medium.com/@Matt. Bartlett/the-evolution-of-mobile-wireless-technology-from-0g-to-5gcf98c80e2323

[5] Elmer E. Rasmuson Library. (2018). Reference Services and Sources. https://library.uaf.edu/ls101-reference-services 
[6] Ghayas, A. (2020, March 3). What do the terms 1G, 2G, 3G, 4G and 5G really mean? Commsbrief.https://commsbrief.com/what-do-the-terms1g-2g-3g-4g-and-5g-really mean/\#: :text=1G\%2C\%202G\%2C\%20 3G\%2C\%204G\%20and\%205G\%20represent\%20the\%20five

[7] Hinchliffe, L. J., \& Eisenberg, C. W.-. (2020, March 23). Academic Library Response to COVID-19: Real-Time Data Gathering and Dissemination. https://scholarlykitchen.sspnet.org/2020/03/23/academic-libraryresponse-to-covid19/

[8] Holst, A. (2018, June 6). Mobile Communications - Statistics \& Facts. Statista.https://www.statista.com/topics/1147/mobilec ommunications/\#: :text=The\%20global\%20mobile\%20data\%20traffic

[9] Hudson, A. (2010). Measuring the impact of cultural diversity on desired mobile reference services. Reference Services Review, 38(2), 299-308. https://doi.org/10.1108/00907321011045052

[10] Internet World Stats. (2020). World Internet Users Statistics and 2019 World Population Stats. Internetworldstats.com. https://www. internetworldstats.com/stats.html

[11] Kataria, S., \& Anbu K, J. P. (2011). Reference Library in the Pocket: Mobile Reference Services for Libraries. International Research: Journal of Library \& Information Science, 1(2), 114-120. http://irjlis. com/wp-content/uploads/2011/11/3_IR044.pdf

[12] Lin, J., Zhao, S., Yi, W., \& Yu, Z. (2017). Current Situation and Development Trend of Mobile Communication Systems. Journal of Secure Communication and System. https://core.ac.uk/download/ pdf/230064769.pdf

[13] Lippincott, J. K. (2009). Mobile Reference: What Are the Questions? The Reference Librarian, 51(1), 1-11. https://doi. org/10.1080/02763870903373016

[14] Maideen, S. (2017). Mobile Technologies for Academic Libraries: An Overview. Emerging Trends in Library and Information Science, 124-129. Retrieved from https://www.researchgate.net/publication/315516134

[15] Mir, M. M. ud in, \& Kumar, S. (2015). Evolution of Mobile Wireless Technology from 0G to 5G. International Journal of Computer Science and Information Technologies, 6(3), 2545-2551. https://ijcsit.com/docs/ Volume\%206/vol6issue03/ijcsit20150603123.pdf

[16] Morris, A. (2018, December 4). South Korea Launches 5G, But Only for Enterprise Users Initially. SDxCentral. https://www.sdxcentral.com/ articles/news/south-korea-launches-5g-but-only-for-enterprise-usersinitially/2018/12/

[17] Murray, L. (2010). Libraries "like to move it, move it." Reference Services Review, 38(2), 233-249. https://doi.org/10.1108/00907321011045007 
98 Re-Envisioning Roles and Responsibilities of Library Professionals in...

[18] O’Dea, S. (2020, February 28). Unique mobile subscribers worldwide 2010-2020. Statista. https://www.statista.com/statistics/371780/uniquemobile-subscribers-worldwide-from-2008/\#statisticContainer

[19] O’Dea, S. (2021, January 19). Mobile data traffic per smartphone worldwide 2014-2024. Statista. https://www.statista.com/ statistics/738977/worldwide-monthly-data-traffic-per-smartphone/

[20] Olatokun, M. W., \& Bodunwa, I. O. (2006). GSM usage at the University of Ibadan. The Electronic Library, 24(4), 530-547. https:// doi.org/10.1108/02640470610689214

[21] Panda, S. (2020). Mobile Librarianship: An Initiative of New Normal. International Research Journal of Multidisciplinary Studies, 6(9), 1525. https://doi.org/10.31235/osf.io/u3rn7

[22] Paul, A. K. J. (2016). Enhancement of Library Services through Mobile Technology A practical framework. In Handle.net (pp. 1-34). https://doi. org/http://hdl.handle.net/10603/190810

[23] Rahane, V. C. (2018). Mobile Technology using in Library services. International Journal of Research in Library Science, 4(2), 23. https://doi.org/10.26761/ijrls.4.2.2018.1294

[24] S., M., \& P., K. (2013). Application of Mobile Technologies to Libraries. DESIDOC Journal of Library \& Information Technology, 33(5), 361366. https://doi.org/https://doi.org/10.14429/djlit.33.5.5098

[25] Shahzad, A., Nawi, N. M., Mahdin, H., Khan, S. N., \& Hamid, N. A. (2020). Recent Advances on Soft Computing and Data Mining. In R. Ghazali, N. M. Nawi, M. M. Deris, \& J. H. Abawajy (Eds.), Advances in Intelligent Systems and Computing. Springer International Publishing. https://doi.org/10.1007/978-3-030-36056-6

[26] Singh, K., \& Nikandia, P. K. (2017). Role of Mobile Technology and their Application in Library Services in Digital Era. International Research : Journal of Library and Information Science, 7(1), 157-166. http://irjlis. com/wp-content/uploads/2017/05/11-IR-392.pdf

[27] Singh, N. (2012). Digital Reference Service in University Libraries: A Case Study of the Northern India. International Journal of Library and Information Studies, 2(4), 1-17. http://www.ijlis.org/img/2012_Vol_2_ Issue_4/1-17.pdf

[28] Tao, D., McCarthy, P. G., Krieger, M. M., \& Webb, A. B. (2009). The Mobile Reference Service: a case study of an onsite reference service program at the school of public health. Journal of the Medical Library Association: JMLA, 97(1), 34-40. https://doi.org/10.3163/1536-5050.97.1.006

[29] Thorpe, C. (2017). Engaging with Our Communities: Future Trends and Opportunities for Reference Services. Journal of the Australian Library and Information Association, 66(4), 406-415. https://doi.org/10.1080/24 750158.2017.1359993 
[30] Upasana (2021). "Whatsapp Usage for Learning Resources and E Resources Sharing Amongst Scholars of Sushant University during Lock down Period: A Study International Journal of Research in Library Science, (IJRLS) Vol 7(2), pp 67-76,

[31] Upasana (2020)" A survey on adoption of digital technologies and knowledge discovery tools to measure in enhancing library services." i-research international" Vol6 (1) 